\title{
Top-Down Fabrication Process of ZnO NWFETs
}

\author{
N.M.J. Ditshego ${ }^{1, a}$, S.M. Sultan ${ }^{2}$ \\ ${ }^{1}$ Electrical, Computer and Telecommunications Engineering Department, CET, \\ Botswana International University of Science and Technology (BIUST), Private bag 16, \\ Palapye, Botswana \\ ${ }^{2}$ School of Electrical Engineering (FKE), Universiti Teknologi Malaysia, 81310 UTM Skudai, Johor \\ Darul Takzim, Malaysia \\ Email: ditshegon@biust.ac.bw
}

Keywords: depletion mode, enhancement mode, field effect transistor, nanowire, remote plasma atomic layer deposition (RPALD), passivation, $\mathrm{ZnO}$ zinc oxide, device, nanosensor

Abstract: $\mathrm{ZnO}$ NWFETs were fabricated with and without $\mathrm{Al}_{2} \mathrm{O}_{3}$ passivation. This was done by developing a new recipe for depositing the thin film of $\mathrm{ZnO}$. By using a high donor concentration of $1.7 \times 10^{18} \mathrm{~cm}^{-3}$ for the thin film, contact resistance values were lowered (passivated device had $\mathrm{R}_{\text {con }}$ $=2.5 \times 10^{4} \Omega$; unpassivated device had $\mathrm{R}_{\text {con }}=3.0 \times 10^{5} \Omega$ ). By depositing $\mathrm{Zn}$ first instead of $\mathrm{O}_{2}$, steep subthreshold slopes were obtained. The passivated device had a subthreshold slope of $225 \mathrm{mV} /$ decade and the unpassivated device had a slope of $125 \mathrm{mV} /$ decade. Well-behaved electrical characteristics have been obtained and the passivated device shows field effect mobility of $10.9 \mathrm{~cm}^{2} / \mathrm{Vs}$ and the un-passivated device shows a value of $31.4 \mathrm{~cm}^{2} / \mathrm{Vs}$. To verify the results, 3D simulation was also carried out which shows that the obtained values of sub-threshold slope translate into interface state number densities of $-1.86 \times 10^{13} \mathrm{~cm}^{-2}$ for the unpassivated device and $3.35 \times 10^{14} \mathrm{~cm}^{-2}$ for the passivated device. The passivated device is suitable for biosensing applications.

\section{Introduction}

Nanowire field effect transistors (NWFETs) can be fabricated using bottom-up or top-down processes [1]. Bottom-up methods involve preparing the nanowires from molecular precursors [1]. The fabrication process has two main approaches: vapour-liquid-solid (VLS) and laser ablation VLS [1]. Both techniques utilized catalyst nanoparticles that are uniformly dispersed on a substrate and gases are flowed over them [2]. The nanowires grow randomly over the substrate and the size is determined by the size of the catalyst nanoparticles [2-4]. The method produces single crystalline nanowires ( NWs) having high quality electrical characteristics [2]. Although bottom-up devices have better electrical characteristics; controlling their orientation, dimension and addressability can be challenging [2-4]. They are also limited by high temperatures during the synthesis process which are typically in the $800-1000{ }^{\circ} \mathrm{C}$ range [1]. Lower fabrication temperatures have been reported but most nanowires with excellent electrical characteristics are still made at these high temperatures. NWFETs fabricated with bottom-up approaches have been reported to exhibit high values of field effect mobility $>2000 \mathrm{~cm}^{2} / \mathrm{Vs}[2-4]$.

Top-down fabrication technology starts with bulk material and uses conventional microelectronics technology to pattern the bulk material into the desired geometry and sizes [1]. This is done through a variety of techniques (such as UV photolithography, e-beam lithography, reactive ion etch, etc) in order to cut, shape, pattern and etch the material [2-4]. These techniques tend to produce highly uniform and well-aligned devices [2]. Their pre-determined orientation and position on the substrate enable the nanowires to be configured into functional devices such as biosensors [2]. This subsequently paves the way for mass production. Whereas the bottom-up tends to produce higher mobility $>2000 \mathrm{~cm}^{2} / \mathrm{Vs}$ [2-4], these top-down nanowire devices tend to suffer from a lower field effect mobility, typically $<50 \mathrm{~cm}^{2} / \mathrm{Vs}[5,6]$.

This paper aims to improve the top-down fabricated ZnO NWFET developed using spacer technique [4,6-14]. The fabricated devices are known to be limited by the contact resistance and 
interface state defects, therefore, in this work these limitations will be addressed by altering the deposition recipe of the $\mathrm{ZnO}$ layer. In addition, a technology for $\mathrm{ZnO}$ surface passivation is developed to prepare the ZnO NWFET towards biosensing applications. The paper shows novelty by being the first to show how $\mathrm{ZnO}$ devices can be converted from enhancement to depletion mode via passivation. No research has ever shown this before for $\mathrm{ZnO}$ devices. Finally, 3-D simulations is carried out to verify that the devices have indeed been optimized.
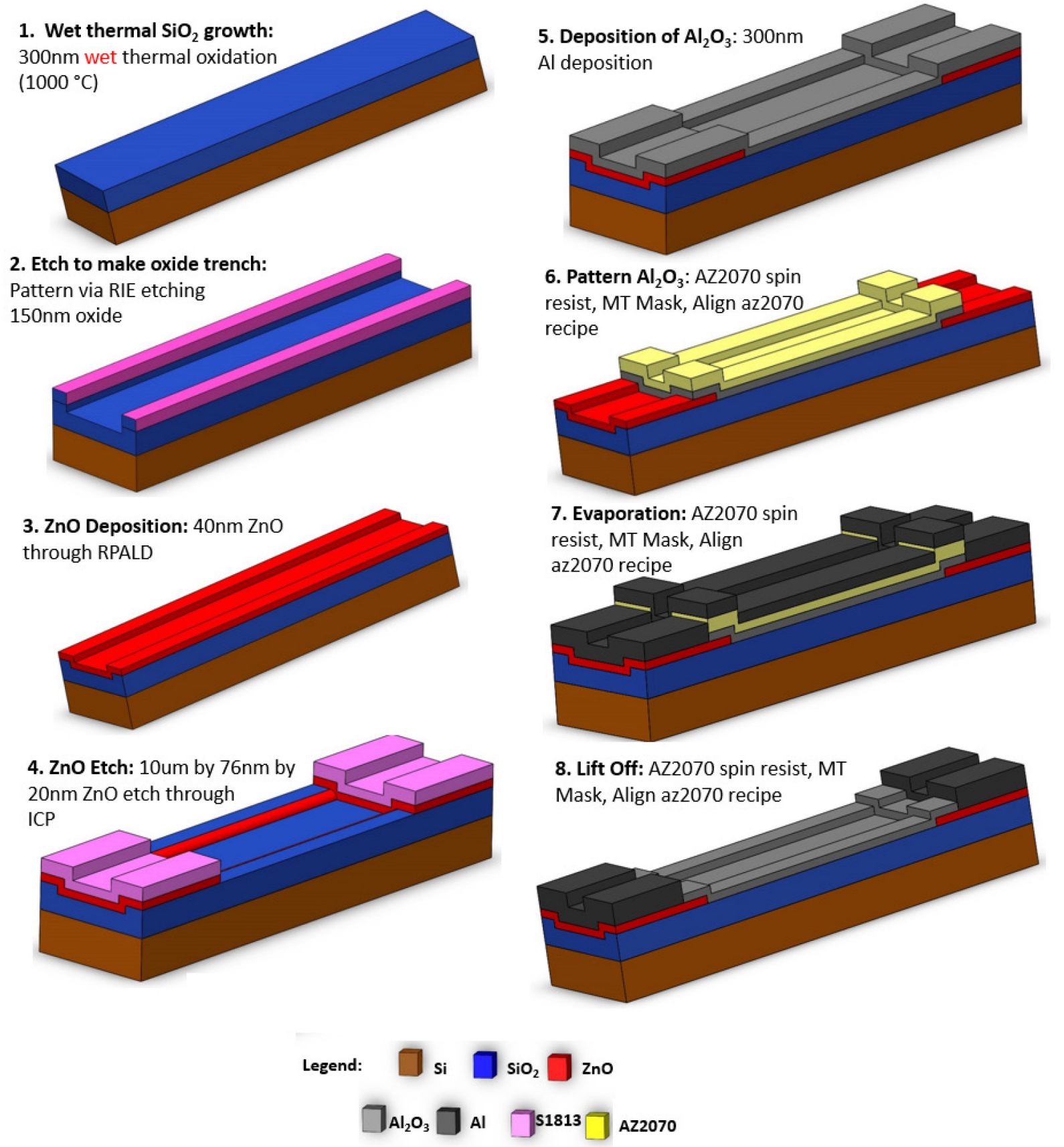

Fig. 1: The fabrication process of passivated and unpassivated $\mathrm{ZnO}$ NWFETs (1) $\mathrm{SiO}_{2}$ insulator grown through wet thermal oxidation having a thickness of $300 \mathrm{~nm}$. (2) RIE anisotropic etch to make a $120 \mathrm{~nm}$ trench on the oxide layer. (3) a $76 \mathrm{~nm} \mathrm{ZnO}$ deposition through RPALD. (4) Anisotropic ICP etch to make nanowires having dimensions of $10 \mu \mathrm{m} \times 120 \mathrm{~nm} \times 20 \mathrm{~nm}$. After this step Al metal is deposited to make unpassivated devices. To make passivated devices, Al is not deposited but $\mathrm{Al}_{2} \mathrm{O}_{3}$ at step 5 through thermal ALD having a thickness of $18 \mathrm{~nm}$. The $\mathrm{Al}_{2} \mathrm{O}_{3}$ passivates the nanowire channel. (6) Patterning and ICP etch of the $\mathrm{Al}_{2} \mathrm{O}_{3}$. (7) Evaporation of $\mathrm{Al}$ metal using the thermal evaporator tool. (8) Removal of unwanted Al through lift-off allowing for patterned metal to be the source and drain. 


\section{Device Fabrication}

The fabrication process for the bottom gated ZnO NWFET is outlined in Fig. 1. The process starts with a cleaning procedures of a $150 \mathrm{~mm}$ diameter of a p-type Si wafer. The wafer was cleaned in fuming nitric acid (FNA) for 10 minutes; then in 'RCA1 and RCA2' for 10 minutes each. RCA1 is a $\mathrm{H}_{2} \mathrm{O}: \mathrm{NH}_{4} \mathrm{OH}: \mathrm{H}_{2} \mathrm{O}_{2}$ solution that chemically attacks organic impurities while $\mathrm{RCA} 2$ is a $\mathrm{H} 2 \mathrm{O}: \mathrm{HCl}: \mathrm{H} 2 \mathrm{O} 2$ solution that attacks and removes metal impurities. RCA cleaning is important to ensure a high quality gate oxide can be grown on the wafer. The wafer afterwards is dipped in hydrofluoric acid (HF) for 30 seconds.

After the cleaning process, a $300 \mathrm{~nm}$ of $\mathrm{SiO}_{2}$ was grown on the wafer using thermal oxidation. The oxide was patterned by photolithography and etched in Reactive Ion Etch (RIE) to form the spacer templates. $\mathrm{SiO}_{2}$ trenches were produced with a depth of $120 \mathrm{~nm}$ and a width of $10 \mu \mathrm{m}$. The RIE trench process utilizes anisotropic etch at a temperature of $20^{\circ} \mathrm{C}, \mathrm{RF}$ power of $200 \mathrm{~W}$, pressure of $20 \mathrm{mT}$ Torr, Ar gas flow of $38 \mathrm{sccm}$ and $\mathrm{CHF}_{3}$ gas flow of $12 \mathrm{sccm}$. A ZnO layer was then deposited on the $\mathrm{SiO}_{2}$ trenches by remote plasma atomic layer deposition (RPALD) using the Oxford Instrument FlexAL system. The deposition process was conducted for 900 cycles. Each cycle consists of a $50 \mathrm{~ms}$ diethyl zinc (DEZ) precursor dose time, a $4 \mathrm{~s}$ Ar purge, a $2.65 \mathrm{~s}$ oxygen plasma, and a final $4 \mathrm{~s}$ Ar purge. The deposition temperature was at $190{ }^{\circ} \mathrm{C}$ and the RF power and pressure were set at $100 \mathrm{~W}$ and 15 mTorr, respectively. RPALD can produce high quality films within temperature range of $120^{\circ} \mathrm{C}$ to $210^{\circ} \mathrm{C}$ depending on other parameters such as $\mathrm{RF}$ power and pressure. The ellipsometer measurement of the deposited $\mathrm{ZnO}$ layer thickness was $76 \mathrm{~nm}$. The $\mathrm{ZnO}$ layer was later etched in Inductively Coupled Plasma (ICP) etch to form the nanowires.

Anisotropic inductively coupled plasma (ICP) etcher and $\mathrm{CHF}_{3}$ gas chemistry was used to etch and pattern the $\mathrm{ZnO}$ layer. This was done at a temperature and pressure of $20^{\circ} \mathrm{C}$ and $10 \mathrm{mTorr}$, respectively. $\mathrm{CHF}_{3}$ gas was kept at a flow rate of $30 \mathrm{sccm}$ while RF and ICP generator powers are kept at $100 \mathrm{~W}$ and $2000 \mathrm{~W}$, respectively.

Fig. 2 shows a cross-sectional SEM of the fabricated $\mathrm{ZnO}$ nanowire. The $\mathrm{ZnO}$ thickness at the edge of the spacer is approximately twice the thickness to the flat surface, hence after the ICP etch, $\mathrm{ZnO}$ at the spacer leaves a thin nanowire having a height of $120 \mathrm{~nm}$ which was equivalent to the height of the $\mathrm{SiO}_{2}$ trench. $\mathrm{ZnO}$ layer at the non-spacer regions were fully etched out in ICP etch. The nanowires were produced on sidewall of the $\mathrm{SiO}_{2}$ trenches. The advantage of this method is the maskless approach and the nanowires are self-aligned to the source and drain. The thickness of the nanowires achieved in this process is $20 \mathrm{~nm}$. The etching process is not optimized and the thickness tends to vary form $\sim 5 \mathrm{~nm}$ to $\sim 30 \mathrm{~nm}$ across a single chip.

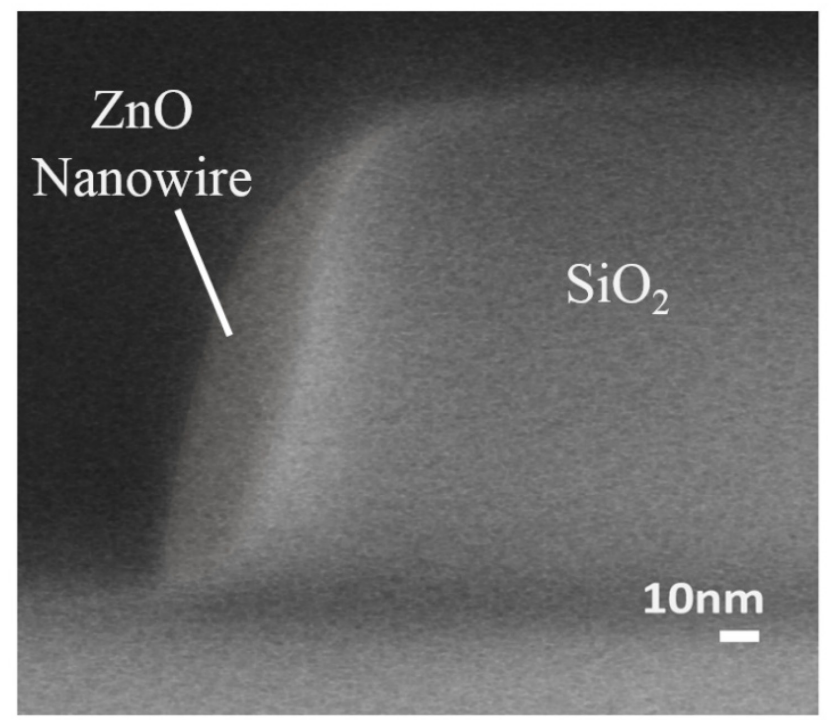

Fig. 2: Cross-sectional SEM image of fabricated high-doped $\mathrm{ZnO}$ nanowire. 
The thermal ALD tool was used to deposit $\mathrm{Al}_{2} \mathrm{O}_{3}$ passivation layer of $18 \mathrm{~nm}$ thick over the $\mathrm{ZnO}$ nanowires at temperature of $200{ }^{\circ} \mathrm{C}$. The process had 163 cycles using trimethyl-aluminium (TMA) precursor for the aluminium source and distilled ionised water for oxidation. The pressure was kept at 1.0 torr while the TMA and $\mathrm{H}_{2} \mathrm{O}$ have a dose of $0.030 \mathrm{sec}$ and $0.075 \mathrm{sec}$, respectively. The aluminium oxide was dry etched from the contact widows using the ICP tool at a temperature and pressure of $20^{\circ} \mathrm{C}$ and 10 mtorr. The gases used for etching were $\mathrm{O}_{2}$ and $\mathrm{C}_{3} \mathrm{~F}_{8}$ having flow rates of $50 \mathrm{sccm}$ and $25 \mathrm{sccm}$.

The wafer was designed with different NWFETs: all use a global back-gate. The back-gated NWFETs have 2, 4, and 16 parallel nanowires of 2, 10, and $20 \mu \mathrm{m}$ channel length, respectively. It was also designed such that each chip had alongside biosensor devices with 100 nanowires. The NWFETs were fabricated using a three mask process: mask NW is used to create trenches that define where the nanowires will be located on the $\mathrm{SiO}_{2}$, mask DP was used to define the $\mathrm{ZnO}$ pads that make up the source and drain and mask MT defines the aluminium electrodes.

Fig. 3 shows a finished device fabricated using the three mask process (mask NW, mask DP and mask MT). The device has two nanowires in parallel. The image was derived using an optical microscope. It shows that the photolithography produced well aligned devices. Fig. 4 shows an optical micrograph of two completed wafers. A ' 6 ' inch wafer contains 66 identical chips, so that it can be measured at different devices across the wafer

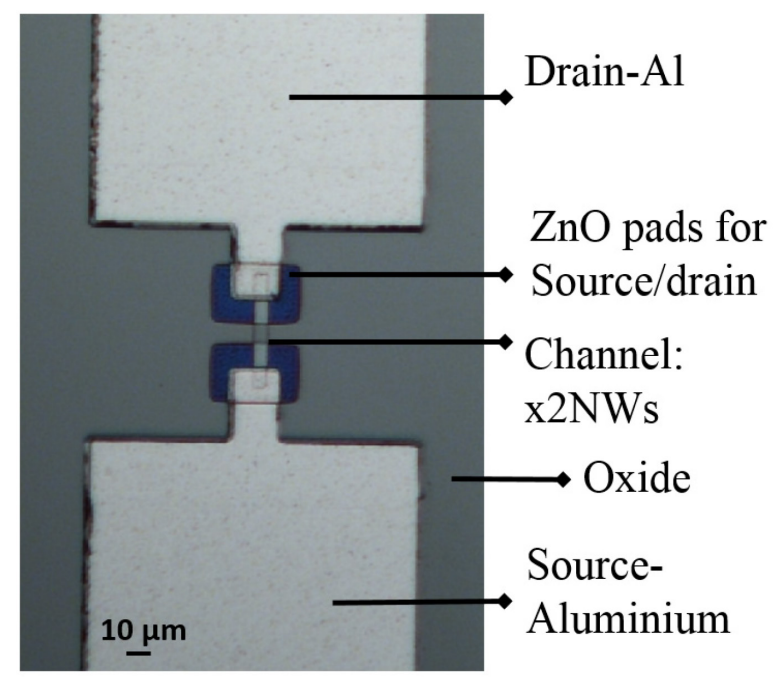

Fig. 3: Optical microscope image of a completed device fabricated using a three mask process (mask NW, mask DP and mask MT). The device has two nanowires in parallel

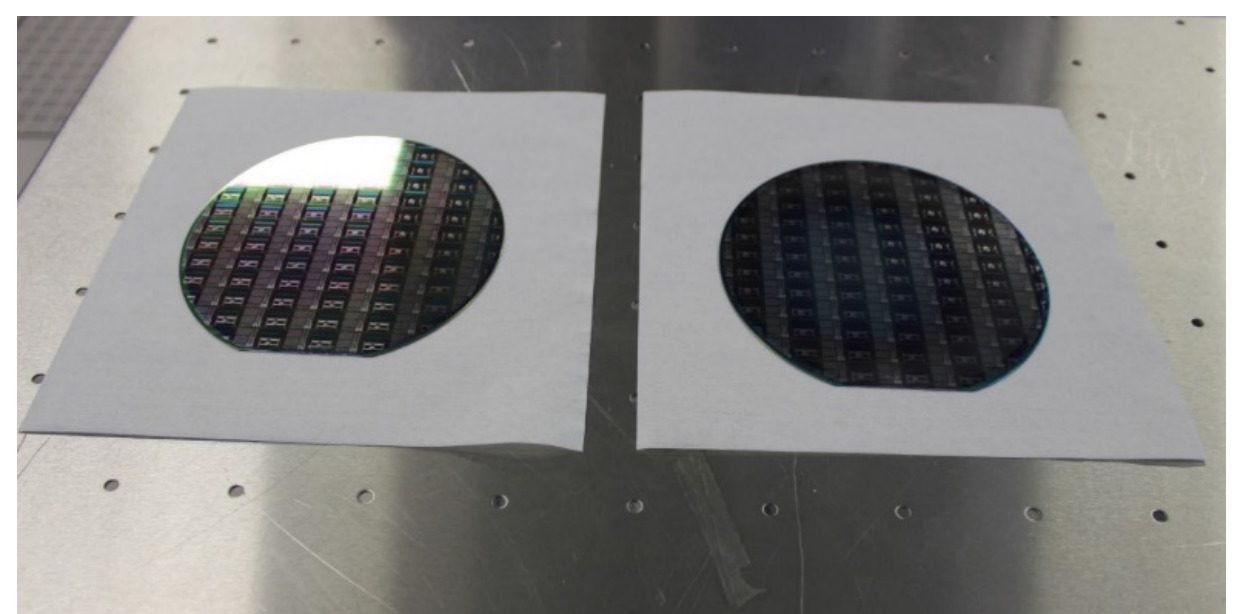

Fig. 4: Optical micrograph showing two completed wafers of the nanowire devices. Each wafer contains 66 identical chips. 
The electrical I-V characterization of the ZnO NWFETs was performed using an Agilent Technologies B1500A semiconductor parametric analyser. Hall measurements were made on the $\mathrm{ZnO}$ layer and the results were compared with results reported by other researchers [4, 6-14].

\section{Process Optimisation}

This work aims to improve an existing process developed by S. M. Sultan et al., [6] on the remote plasma atomic layer deposition (RPALD) process. All other steps were kept relatively the same. RPALD is capable of producing highly conformal and quality films [8]. The process is cyclic and is based on the number of reactants. For $\mathrm{ZnO}$ films, the cycle depends on two reactants: metallisation and oxidation. Metallisation uses diethyl zinc (DEZ) as the zinc (Zn) metal precursor. Purge and pump steps are used to separate the execution of the reactants and to remove any byproducts. Before deposition: the wafer (substrate) is pre-heated to a temperature used for deposition $\left(190{ }^{\circ} \mathrm{C}\right)$ and it is also cleaned with an $\mathrm{O}_{2}$ plasma to remove any polymer layer. During the metallisation step, the DEZ $\left(\mathrm{Zn}\left(\mathrm{C}_{2} \mathrm{H}_{5}\right)_{2}\right)$ is absorbed onto the surface of the wafer, then on another step, $\mathrm{O}_{2}$ is delivered to react with the absorbed DEZ [2-10].

The existing process [6] is as follows: 333 cycles of an initial $4.0 \mathrm{~s}$ Ar purge, a $4.0 \mathrm{~s}$ oxygen plasma, a $1.0 \mathrm{~s}$ dose exposure to diethyl zinc (DEZ) and a final $2.0 \mathrm{~s}$ Ar purge. This was carried out at a temperature of $190{ }^{\circ} \mathrm{C}$ with $\mathrm{RF}$ power of $100 \mathrm{~W}$ and pressure of 15 mtorr. The ZnO layer achieved was $36 \mathrm{~nm}$. The $\mathrm{ZnO}$ layer produced had a sheet resistance of $19.9 \times 10^{6} \Omega / \mathrm{sq}$ and a donor concentration of $2.0 \times 10^{16} \mathrm{~cm}^{-3}$. To improve the $\mathrm{ZnO}$ film properties, changes were made to the number of cycles, the order of the reactants, the oxygen plasma dose time and the DEZ dose time. These changes affected the doping, contact resistance and interface state charge, as will be discussed in the next section.

\section{Contact Resistance Reduction}

From the device fabricated by S. M. Sultan et al., [6] the $\mathrm{Al} / \mathrm{ZnO}$ contact resistance, $\mathrm{R}_{\text {con }}$ measured was $1.8 \times 10^{8} \Omega$, and a sheet resistance of $2.09 \times 10^{7} \Omega / \mathrm{sq}$ was obtained. Consequently, the contacts between Aluminium and $\mathrm{ZnO}$ exhibited Schottky behaviour [6]. In order to reduce the contact resistance, most researchers [5-15] use annealing to improve the film quality and the contacts, with temperatures $>500{ }^{\circ} \mathrm{C}$. The problem with aluminium is that it has a low melting temperature of $660^{\circ} \mathrm{C}$ and is also a p-type dopant that compensates the natural n-type doping of the $\mathrm{ZnO}$ layer. The highest temperature that can be used for annealing Aluminium is around $400{ }^{\circ} \mathrm{C}$. Therefore, researchers [4, 6-14] anneal $\mathrm{Al}$ contacts at temperatures between $300{ }^{\circ} \mathrm{C}$ and $400{ }^{\circ} \mathrm{C}[6]$. However, the contact resistance did not improve significantly hence there is a need for an alternative technique to be used which is to use higher doping on the $\mathrm{ZnO}$ layer.

Higher doping was used to reduce contact resistance and sheet resistance. This was achieved by developing a new recipe for the RPALD. Three main parameters were altered: film thickness, DEZ dose time and $\mathrm{O}_{2}$ dose time. DEZ dose time was reduced from a value of $1.0 \mathrm{~s}$ to a value of $50 \mathrm{~ms}$, while $\mathrm{O}_{2}$ dose time was reduced from $4.0 \mathrm{~s}$ to $2.65 \mathrm{~s}$. Researchers [1-20] have shown that doping concentration in $\mathrm{ZnO}$ depends on oxygen defects (oxygen interstitials $\left(\mathrm{O}_{\mathrm{i}}\right)$, oxygen antisite defects $\left(\mathrm{O}_{\mathrm{Zn}}\right)$, and oxygen vacancies $\left.\left(\mathrm{V}_{\mathrm{o}}\right)\right)$. By reducing the DEZ dose time from $1.0 \mathrm{~s}$ to $50 \mathrm{~ms}$, it caused the $\mathrm{O}$ content to be much higher than the $\mathrm{Zn}$ content which increased the doping concentration. This means oxygen interstitials $\mathrm{O}_{i}$ and oxygen antisite defects $\mathrm{O}_{\mathrm{Zn}}$ have more effect on the doping concentration than oxygen vacancies $\mathrm{V}_{\mathrm{o}}$.

\section{Interface States Charge}

From the simulation study, it was found the device fabricated by S. M. Sultan et al., [6] had high interface state charge density that needed to be reduced [6]. Normally interface state charge is reduced by annealing and wet cleaning [5-16] process. A high temperature annealing cannot be 
used to improve the film properties as aluminium compensates the natural $\mathrm{n}$-type doping of the $\mathrm{ZnO}$ layer. In addition, this work follows the same cleaning procedure as outlined [6].

To reduce the interface state charge, the $\mathrm{ZnO}$ deposition recipe was modified. Instead of flowing $\mathrm{O}_{2}$ first into the chamber, DEZ was flowed first. $\mathrm{An}_{2}$ plasma tends to damage the $\mathrm{SiO}_{2}$ surface, thereby increasing the amount of interface state charge. The deposition of a zinc layer first provides some protection against surface damage from the $\mathrm{O}_{2}$ plasma.

\section{Passivation}

An unpassivated device cannot be used as a biosensor because the $\mathrm{ZnO} \mathrm{NW}$ channel can be etched by the bioanalytic solutions [18]. Therefore an insulating layer is needed on top of the $\mathrm{ZnO}$ layer. The device has a $\mathrm{SiO}_{2}$ layer beneath the $\mathrm{ZnO}$. However, for the upper surface passivation layer, $\mathrm{Al}_{2} \mathrm{O}_{3}$ is used as an alternative to $\mathrm{SiO}_{2}$. This is because it can be deposited at a lower temperature $[16,17]$. Also, its dielectric constant is between 9.0 and 10.1 which is higher compared to $\mathrm{SiO}_{2}$ in which the dielectric constant is only 3.9. High dielectric constant is desired and forms good diffusion barriers between the channel and the bioanalytes which makes it more sensitive than $\mathrm{SiO}_{2}$. This means that the physical thickness of the gate dielectric $\left(\mathrm{Al}_{2} \mathrm{O}_{3}\right)$ can be reduced more than $\mathrm{SiO}_{2}$ without losing sensitivity to charge and with no adverse leakage currents [9-20].

\section{Results}

The $\mathrm{ZnO}$ layer produced from the optimized technique was characterized in 4-point probe Hall measurement. The $\mathrm{ZnO}$ layers had a sheet resistance of $1.1 \times 10^{4} \Omega / \mathrm{sq}$ which is 2 order magnitude lower than reported [6]. The donor concentration was measured to be at $1.7 \times 10^{18} \mathrm{~cm}^{-3}$, which is higher by 2 order of magnitude than reported [6]. Fig. 5 shows the results of thickness and uniformity measurements for the thermally grown $\mathrm{SiO}_{2}$ and the RPALD deposited $\mathrm{ZnO}$. The $\mathrm{SiO}_{2}$ has an average thickness of $292 \mathrm{~nm}$ and uniformity of $1.21 \%$. The $\mathrm{ZnO}$ has an average thickness of $76 \mathrm{~nm}$ and a uniformity of $2.85 \%$.

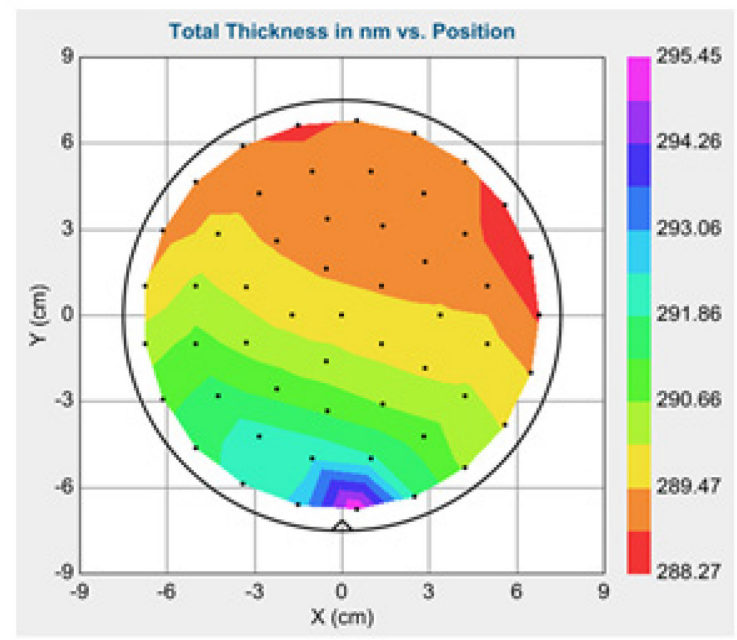

(a)

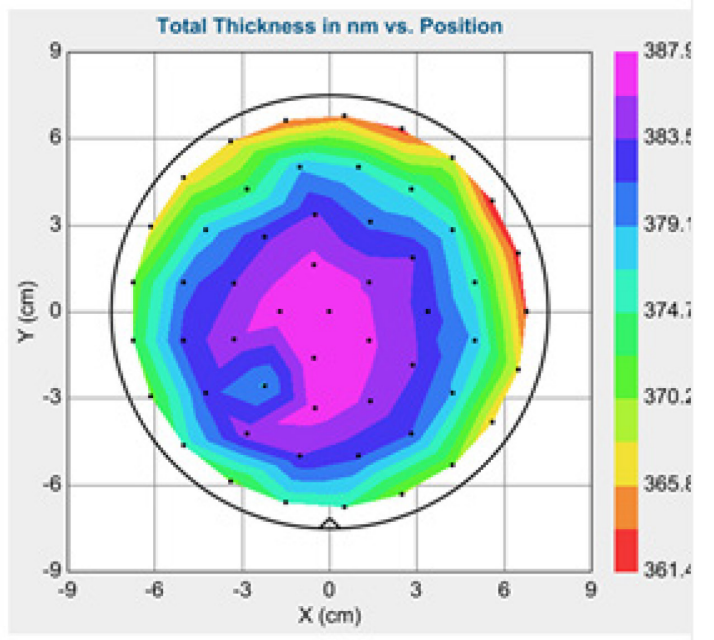

(b)

Fig. 5: Ellipsometry measurements showing the thickness uniformity of the thermal $\mathrm{SiO} 2$ and the RPALD-ZnO layers (a) $\mathrm{SiO} 2$ uniformity (b) $\mathrm{ZnO}$ film uniformity.

To give an indication of device uniformity, Fig. 6 shows $\mathrm{I}_{\mathrm{DS}} \mathrm{V}_{\mathrm{DS}}$ characteristics for the same type of NWFET device measured on five different chips. The chips were derived from a single wafer and only devices with a 100 nanowires in parallel were measured. Well behaved output characteristics are obtained with transistor operation up to $40 \mathrm{~V}$ and above. The uniformity of the transistor characteristics was assessed by measuring the drain current at a drain voltage of $40 \mathrm{~V}$ with a standard percentage deviation of $<23 \%$. All devices across the wafer gave well behaved transistor characteristics. 


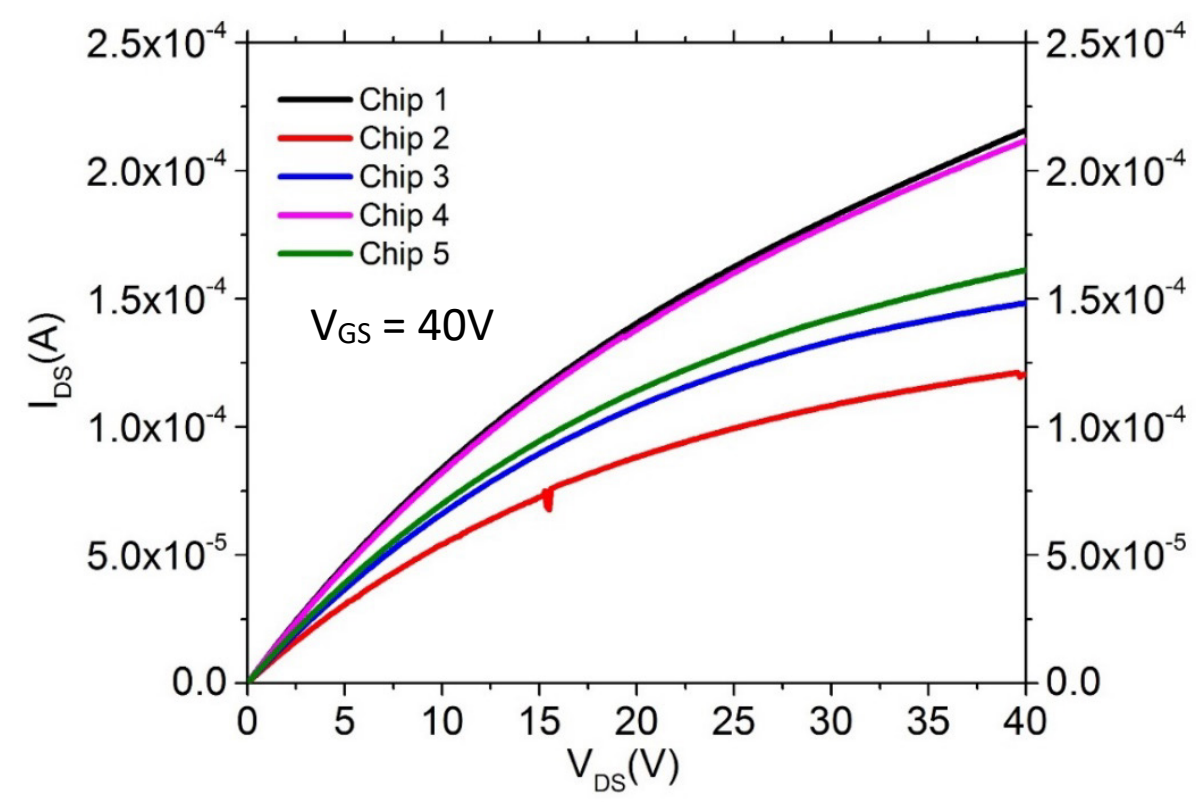

Fig. 6: $\mathrm{I}_{D S} \mathrm{~V}_{\mathrm{DS}}$ characteristics for the same type of $\mathrm{ZnO}$ NWFET device measured on different chips at $V_{G S}$ at $40 \mathrm{~V}$. The NWFET has 100 parallel nanowires and a channel length of $\mathrm{L}=20 \mu \mathrm{m}$.

\section{Un-Passivated NWFET Device}

Fig. 7 shows typical un-passivated ZnO NWFET characteristics for devices measured in air and in dark. The device has two nanowires in parallel and a channel length of $8.6 \mu \mathrm{m}$. The NWFET is ntype with a donor concentration of $1.7 \times 10^{18} \mathrm{~cm}^{-3}$ and operates in enhancement mode with a positive threshold voltage of $6.5 \mathrm{~V}$. The device was expected to be depletion mode operation because it is intrinsically n-type with high doping concentration. However, the I-V characteristics show enhancement mode behaviour. This can be due to surface charges accumulated on the surface of the $\mathrm{ZnO}$ nanowires.

The output characteristic in Fig. 7 (a) shows a well-defined linear region at low bias, clear pinchoff and excellent saturation at high bias. The sub-threshold characteristic in Fig. 7 (b) shows an excellent sub-threshold slope of $125 \mathrm{mV} /$ decade and a threshold voltage of $6.5 \mathrm{~V}$. These characteristics are close to ideal especially the subthreshold slope which is close to the ideal value of $60 \mathrm{mV} /$ decade. A threshold voltage of $6.5 \mathrm{~V}$ was obtained by extrapolating the linear $\mathrm{IDS}_{\mathrm{DS}} / \mathrm{V}_{\mathrm{GS}}$ characteristic in Fig. 7 (b). The theoretical threshold voltage for the device was also calculated and found to be $9.8 \mathrm{~V}$. The equation assumed that surface potential $\emptyset_{\mathrm{SBB}}=\emptyset_{\mathrm{B}} / 2$ and that interface state charge $\left(\mathrm{Q}_{\text {IT }}\right)$ had more effect than the fixed charge $\left(\mathrm{Q}_{\mathrm{f}}\right)$. $\mathrm{Q}_{\text {IT }}$ is derived from the subthreshold slope equation. Surface potential $\left(\emptyset_{\mathrm{SBB}}\right)$ is also known as surface barrier height whereas $\emptyset_{\mathrm{B}}$ stands for surface band bending. 


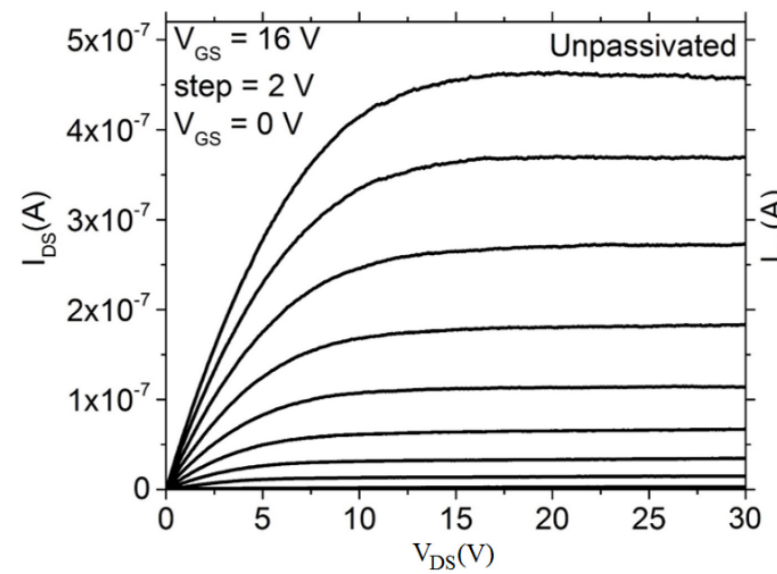

(a)

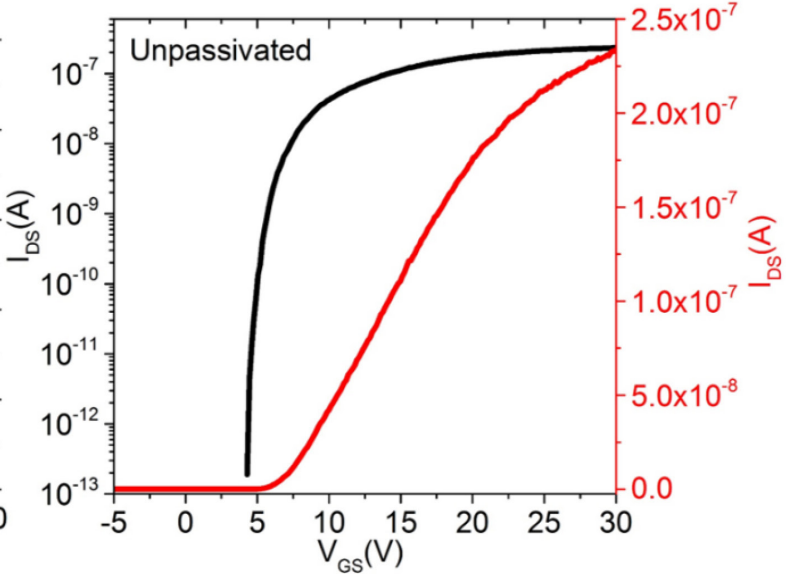

(b)

Fig. 7: Electrical characteristics of an unpassivated ZnO NWFET (a) $\mathrm{I}_{D S} \mathrm{~V}_{\mathrm{DS}}$ characteristic with a $\mathrm{V}_{\mathrm{GS}}$ drive from $0 \mathrm{~V}$ to $16 \mathrm{~V}$ (b) $\mathrm{I}_{\mathrm{DS}} \mathrm{V}_{\mathrm{GS}}$ characteristics with $\mathrm{V}_{\mathrm{DS}}=1.0 \mathrm{~V}$. The NWFET has two parallel nanowires and a channel length of $\mathrm{L}=8.6 \mu \mathrm{m}$.

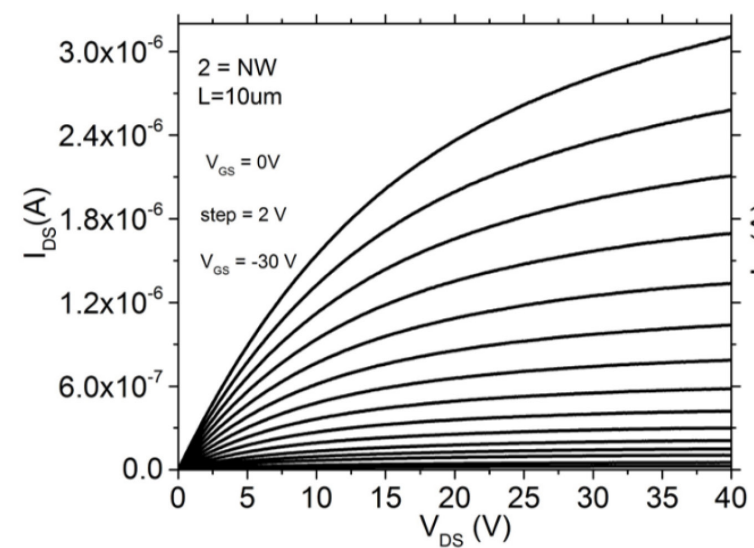

(a)

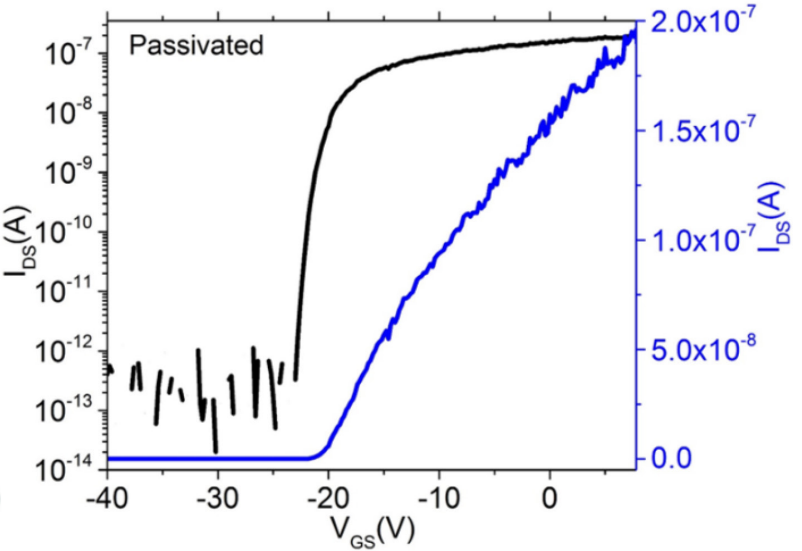

(b)

Fig. 8: Electrical characteristics of a passivated $\mathrm{ZnO}$ NWFET (a) $\mathrm{I}_{D S} \mathrm{~V}_{\mathrm{DS}}$ characteristic with a $\mathrm{V}_{G S}$ drive from $-30 \mathrm{~V}$ to $0 \mathrm{~V}$ (b) $\mathrm{IDS}_{\mathrm{GS}}$ characteristic with $\mathrm{V}_{\mathrm{DS}}=1.0 \mathrm{~V}$. The NWFET has two parallel nanowires and a channel length of $\mathrm{L}=8.6 \mu \mathrm{m}$.

\section{Passivated NWFET Device}

Fig. 8 shows typical passivated ZnO NWFET electrical characteristics measured in air and darkness. Darkness is used because the device is sensitive to light. This is the same type of device as the un-passivated one, hence, it has two nanowires in parallel and a channel length of $8.6 \mu \mathrm{m}$. The NWFET is n-type with a donor concentration of $1.7 \times 10^{18} \mathrm{~cm}^{-3}$ and has a negative threshold voltage of $-20.1 \mathrm{~V}$. The device therefore shows depletion mode operation. The output characteristic in Fig. 8 (a) shows a well-defined linear region at low bias, but pinch-off and saturation regions are not as well-defined at high currents as for the un-passivated device. Fig. 8 (b) shows a sub-threshold slope of $225 \mathrm{mV} /$ decade, an off current of around $1.0 \times 10^{-13} \mathrm{~A}$.

Fig. 9 compares the un-passivated and passivated devices. These results shows novelty by being the first to show how $\mathrm{ZnO}$ devices can be being converted from enhancement to depletion mode via passivation. The results show a threshold voltage shift of $26.6 \mathrm{~V}$. All devices were measured in air and in darkn with $\mathrm{V}_{\mathrm{DS}}=1.0 \mathrm{~V}$. The passivated and un-passivated devices have comparable currents of $0.29 \times 10^{-6} \mathrm{~A}$ and $0.28 \times 10^{-6} \mathrm{~A}$, respectively at $\mathrm{V}_{\mathrm{GS}}=40 \mathrm{~V}$. These results suggest that contact resistance is lower in the passivated and un-passivated devices compared to results reported [6]. This is due to the higher doping concentration in the $\mathrm{ZnO}$ layer obtained in the current work. The subthreshold slope is changed from $125 \mathrm{mV} /$ decade for the un-passivated device to $225 \mathrm{mV} /$ decade for the passivated device, which are both better than the value of $1500 \mathrm{mV} /$ decade reported [6]. The 
passivated device has a maximum peak transconductance, $\mathrm{g}_{\mathrm{m}}$ of $5.2 \times 10^{-9} \mathrm{~S}$ compared with $1.5 \mathrm{x}$ $10^{-8} \mathrm{~S}$ for the un-passivated device. However, device [6] obtained from the previous process has a maximum $g_{\mathrm{m}}$ of $1.0 \times 10^{-8} \mathrm{~S}[6]$. Values of field effect mobility were calculated from $\mathrm{g}_{\mathrm{m}}$ and found to be $10.9 \mathrm{~cm}^{2} / \mathrm{Vs}, 31.4 \mathrm{~cm}^{2} / \mathrm{Vs}$ and $10.0 \mathrm{~cm}^{2} / \mathrm{Vs}$ obtained for passivated, un-passivated and device from literature [6], respectively.

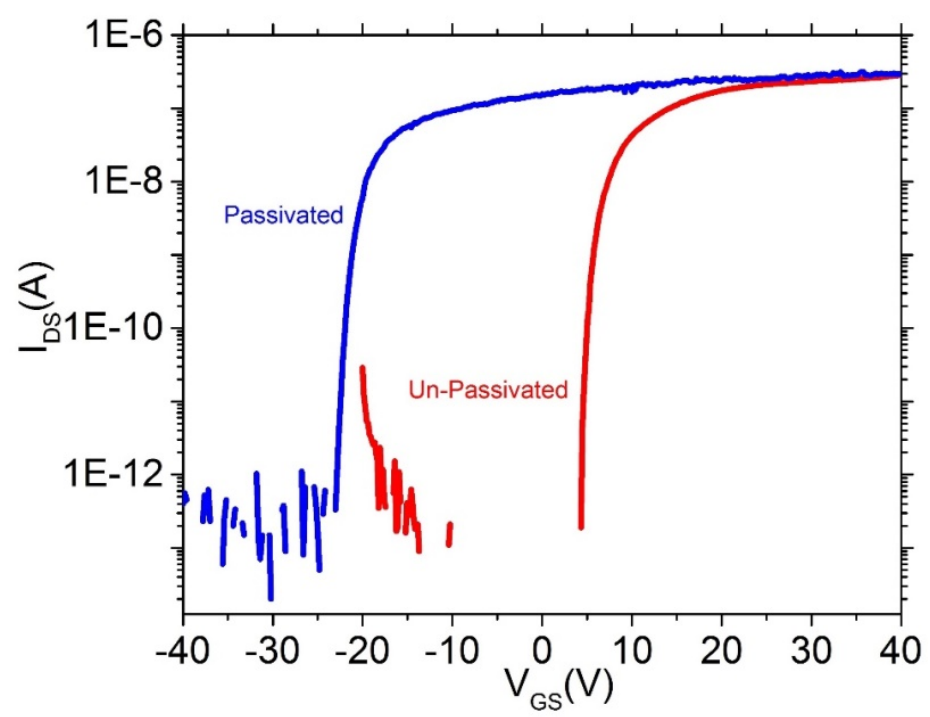

Fig. 9: Comparison of passivated and un-passivated $\mathrm{ZnO}$ NWFETs. These are $\mathrm{IDS}_{\mathrm{GS}}$ characteristics with $\mathrm{V}_{\mathrm{DS}}=1.0 \mathrm{~V}$.

\section{Discussion}

\section{Contact resistance reduction}

The Transmission line method (TLM) was used to extract values of contact resistance and sheet resistance. The passivated device has a contact resistance $R_{\text {con }}$ of $2.5 \times 10^{4} \Omega$, and a sheet resistance of $1.1 \times 10^{4} \Omega / \mathrm{sq}$. Meanwhile, the un-passivated device has a contact resistance $\mathrm{R}_{\text {con }}$ of $3.0 \times 10^{5} \Omega$, and a sheet resistance of $2.8 \times 10^{5} \Omega /$ sq. The two results are significantly better than those reported in literature [4, 6-14].

The above results have shown that the new RPALD process has led to lower values of contact resistance in both unpassivated and passivated devices. This has been achieved by increasing the doping concentration in the deposited $\mathrm{ZnO}$ layer from $2.0 \times 10^{16} \mathrm{~cm}^{-3}$ in the previous process [6] to $1.7 \times 10^{18} \mathrm{~cm}^{-3}$ in an unpassivated $\mathrm{ZnO}$ layer. The literature device [6] exhibited Schottky-diode contacts as can be seen in Fig.10 from the slow turn-on of the transistor at low drain bias. In contrast the results in Fig 7 (a) and Fig. 8 (a) show perfectly linear characteristics at low drain bias, indicating that the contacts are ohmic. These lower values of contact resistance have led to increased values of drain current, as can be seen in Fig.9. 


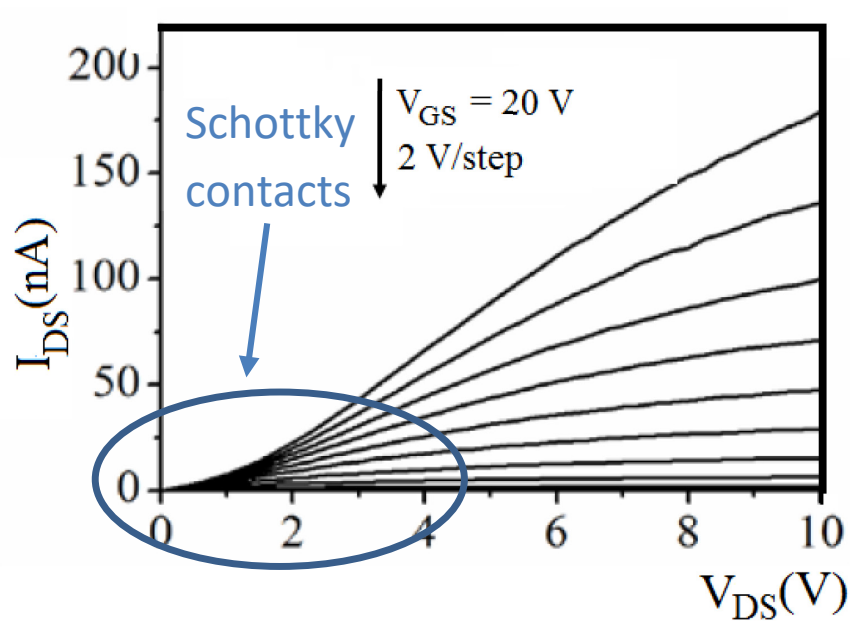

Fig. 10: Schottky-diode contacts characteristics of literature device [6].

\section{Interface states charge}

The new RPALD process has also led to lower values of interface state density, as can be seen from the improved values of sub-threshold slope. This was achieved by starting the $\mathrm{ZnO}$ deposition process with a zinc dose step instead of the oxygen dose step reported [6]. Values of interface state density will be estimated from device simulations later in this paper.

A passivation process has been successfully developed using atomic layer deposited aluminium oxide. The passivated devices show well behaved transistor characteristics. However, the threshold voltage is much lower $(-20.1 \mathrm{~V})$ compared with unpassivated device $(6.5 \mathrm{~V})$. Thus at zero bias, the unpassivated transistor is off (enhancement mode), while the passivated transistor is on (depletion mode). This suggests that the unpassivated device has much more negative fixed charge on the $\mathrm{ZnO}$ surface that the passivated device has on the $\mathrm{Al}_{2} \mathrm{O}_{3}$ surface. Alternatively, the $\mathrm{Al}_{2} \mathrm{O}_{3}$ layer may contain significant positive charge that compensates the negative surface charge. Furthermore, the passivated devices exhibit a higher subthreshold slope than the unpassivated devices (225 $\mathrm{mV} /$ decade compared with $125 \mathrm{mV} /$ decade). This suggests that there are a significant number of interface states at the $\mathrm{ZnO} / \mathrm{Al}_{2} \mathrm{O}_{3}$ interface, which might be due to the use of an acetone/IPA clean prior to $\mathrm{Al}_{2} \mathrm{O}_{3}$ deposition.

\section{Comparing the results obtained with various ZnO NWFETs}

Fig. 11 compares fourteen (14) different ZnO NWFETs fabricated by different authors using a variety of methods [6, 21-33]. The graph is plotted with field effect mobility against the subthreshold slope which are two important device parameters that determine ZnO NWFET performance. The nanowires were fabricated using top-down and bottom-up (self-assembled) processes. Self-assembled processes tend to display very high field effect mobility which is normally above $200 \mathrm{~cm}^{2} / \mathrm{Vs}$; whereas the top-down have lower mobility values. Most of the top-down fabricated devices have mobility $<1.0 \mathrm{~cm}^{2} / \mathrm{Vs}$ with around three papers giving a mobility $>10.0 \mathrm{~cm}^{2} / \mathrm{Vs}$. As stated before, values of field effect mobility obtained are $31.4 \mathrm{~cm}^{2} / \mathrm{Vs}$ and $10.0 \mathrm{~cm}^{2} / \mathrm{Vs}$ for passivated, un-passivated and device, respectively. The figure below shows were such mobility lays. The difference in the mobility may be due to the fact that self-assembled nanowires are single-crystal, whereas top-down nanowires are polycrystalline. Nonetheless, topdown techniques are desirable as they currently pave way for mass production and will be pursued in this research investigation. 







\section{D TCAD Simulation: comparing experiment with 3D simulation}

The electrical results obtained for the two devices (passivated and unpassivated) were then interpreted using 3D simulations. Two Silvaco products were used: Devedit and Atlas. The 3D device structures were developed using Devedit, whereas electrical characteristics and bias conditions were simulated through Atlas. The research investigation uses Devedit over Athena software because Devedit has a more advanced mesh definition which allows for greater accurate and precise output results. Devedit also allows for direct 3D interfacing with Atlas whereas it is impossible with the Athena software. There are several Atlas numerical methods that can be used for calculating device output results and these include: gummel, newton, direct and block. Block cannot be used in 3D simulation and gummel is very slow to utilize. Therefore, the numerical methods used throughout the simulation are newton and direct. The aim of the 3D simulation is to show that the devices have been optimised, therefore have less interface state charge, fixed charge and contact resistance than other devices reported [4, 6-14]. Fitting of the experimental results using simulations always starts with default parameters as given in Table 1.

Table 1: Parameters and their values for passivated and unpassivated devices for TCAD simulation.

\begin{tabular}{|l|l|l|l|}
\hline Parameter & $\begin{array}{l}\text { Default Simulation } \\
\text { values }\end{array}$ & Passivated Device & Unpassivated Device \\
\hline $\mathbf{N}_{\text {TA }}$ & $4.0 \times 10^{17} \mathrm{~cm}^{-3}$ & $1.55 \times 10^{18} \mathrm{~cm}^{-3}$ & $9.1 \times 10^{17} \mathrm{~cm}^{-3}$ \\
\hline $\mathbf{N}_{\text {GA }}$ & $3.0 \times 10^{16} \mathrm{~cm}^{-3}$ & $5.79 \times 10^{16} \mathrm{~cm}^{-3}$ & $3.79 \times 10^{16} \mathrm{~cm}^{-3}$ \\
\hline $\mathbf{E}_{\text {GA }}$ & $1.7 \mathrm{eV}$ & $1.7 \mathrm{eV}$ & $1.7 \mathrm{eV}$ \\
\hline $\mathbf{W}_{\text {GA }}$ & $0.21 \mathrm{eV}$ & $0.21 \mathrm{eV}$ & $0.21 \mathrm{eV}$ \\
\hline $\mathbf{W}_{\mathbf{T A}}$ & $0.14 \mathrm{eV}$ & $0.14 \mathrm{eV}$ & $0.14 \mathrm{eV}$ \\
\hline $\mathbf{E}_{\mathbf{C}}$ & $3.4 \mathrm{eV}$ & $3.4 \mathrm{eV}$ & $3.4 \mathrm{eV}$ \\
\hline $\mathbf{Q}_{\mathbf{f}}$ & $3.0 \times 10^{10} \mathrm{~cm}^{-2}$ & $7.31 \times 10^{12} \mathrm{~cm}^{-2}$ & $-3.0 \times 10^{11} \mathrm{~cm}^{-2}$ \\
\hline $\mathbf{R}_{\mathbf{c o n}}$ & $10 \Omega$ & $3.0 \times 10^{6} \Omega$ & $3.0 \times 10^{5} \Omega$ \\
\hline
\end{tabular}

Fig. 12 shows the default 3D simulation of a ZnO NWFET in comparison with the measured characteristics for passivated and unpassivated devices. Default 3D simulations were executed using the default parameter values from Table 1. The default simulation gives a higher current at high gate bias and a steeper sub-threshold slope. The simulated value of sub-threshold slope is 100 $\mathrm{mV} /$ decade, compared with the measured value of $225 \mathrm{mV} /$ decade for the passivated device and $125 \mathrm{mV} /$ decade for the unpassivated device. The similar value of sub-threshold slope for the simulated and measured unpassivated device is encouraging because it means that the unpassivated device has a small interface state charge which is a huge improvement over the devices [4, 6-14].

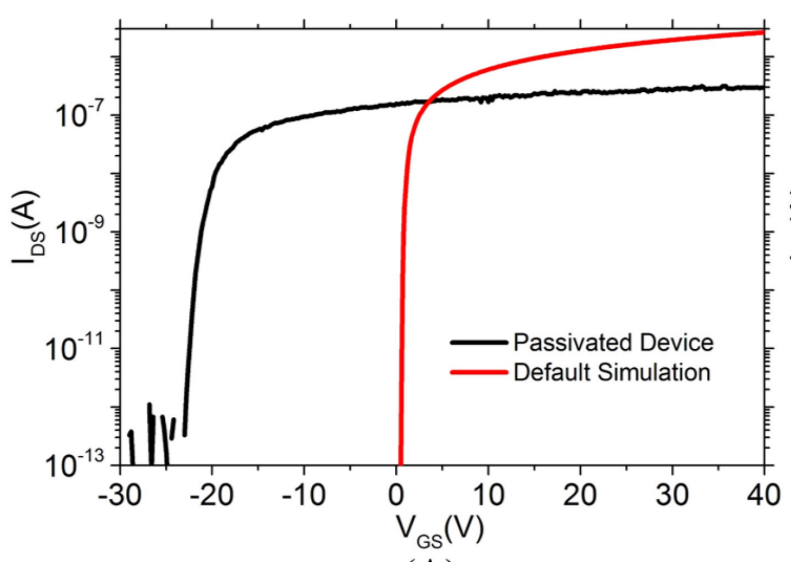

(A)

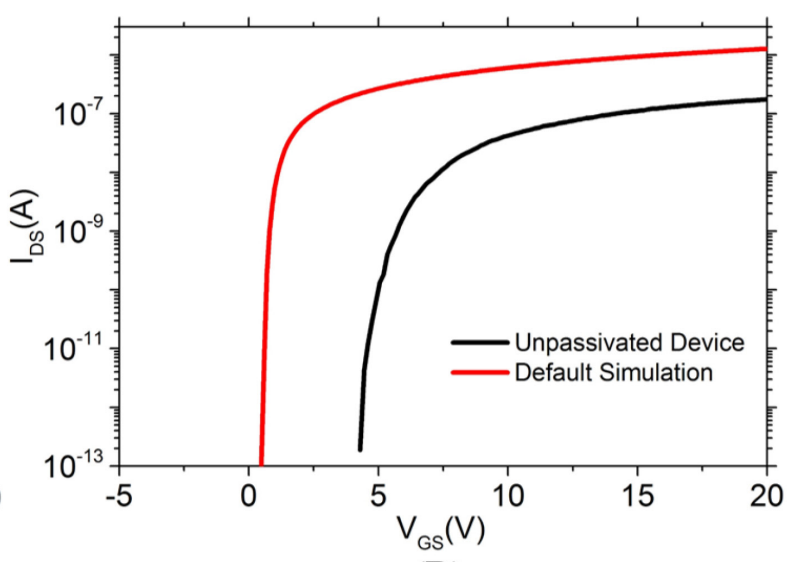

(B)

Fig.12: Default 3D simulation of ZnO NWFET compared with (a) passivated and (b) unpassivated devices. $\mathrm{V}_{\mathrm{DS}}$ is fixed at $1.0 \mathrm{~V}$. 
Next, the fixed charge parameter $\left(\mathrm{Q}_{\mathrm{f}}\right)$ in the simulation was altered to fit the simulation results with experiment. As shown in Fig.13, a positive fixed charge number of $+7.31 \times 10^{12} \mathrm{~cm}^{-2}$ is needed to fit the characteristic of the passivated device and a negative fixed charge number of $-3.0 \times 10^{11} \mathrm{~cm}^{-}$ 2 to fit the characteristic of the unpassivated device.



(A)

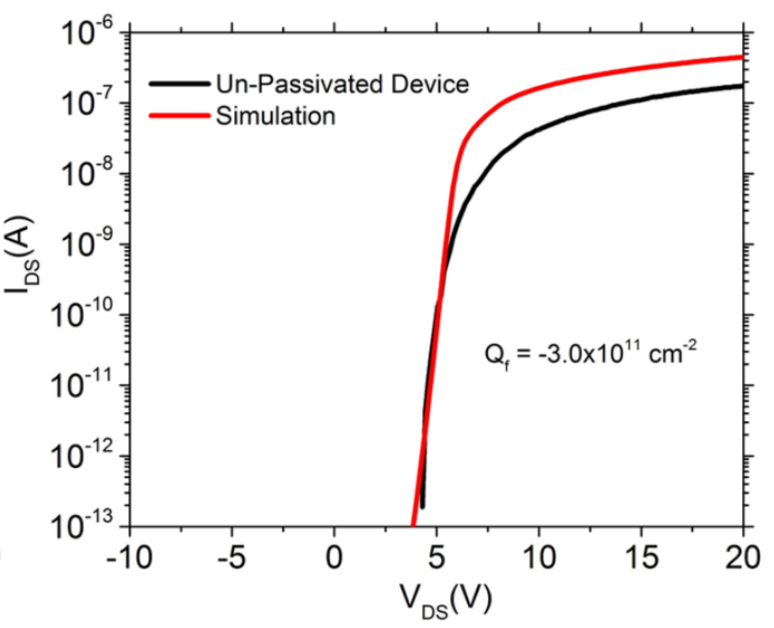

(B)

Fig. 13: $3 \mathrm{D}$ Simulation of the $\mathrm{ZnO}$ NWFET compared with (a) passivated and (b) unpassivated devices after increasing or decreasing the fixed charge $\left(\mathrm{Q}_{\mathrm{f}}\right)$. $\mathrm{V}_{\mathrm{DS}}$ is fixed at $1.0 \mathrm{~V}$.

The subthreshold slope of the unpassivated device fits well with simulation. However, the subthreshold slope of the passivated device does not agree well hence interface state charge was introduced in the simulation so as to better fit the measured characteristic of the passivated device. In Fig.14 the interface state charge parameter $\left(\mathrm{N}_{\mathrm{GA}}\right)$ was the only parameter modified in the simulation of the passivated device to fit the subthreshold slope. It can be seen that the measured characteristic can be well fitted at currents below $1 \mathrm{nA}$. $\mathrm{N}_{\mathrm{GA}}$ can be converted into an interface state density using the parameters in Table. ' $E$ ' is assumed to equal the band-gap of $\mathrm{ZnO}$, which is a value that gives the highest value of interface state density. This gives an interface state density of $9.1 \times 10^{17} \mathrm{~cm}^{-3}$ for the unpassivated device and $1.5 \times 10^{18} \mathrm{~cm}^{-3}$ for the passivated device. These values are higher than that typically obtained for the $\mathrm{Si} / \mathrm{SiO}_{2}$ interface, but are reasonable for a $\mathrm{ZnO} / \mathrm{SiO}_{2}$ interface that was fabricated using low temperature processing.

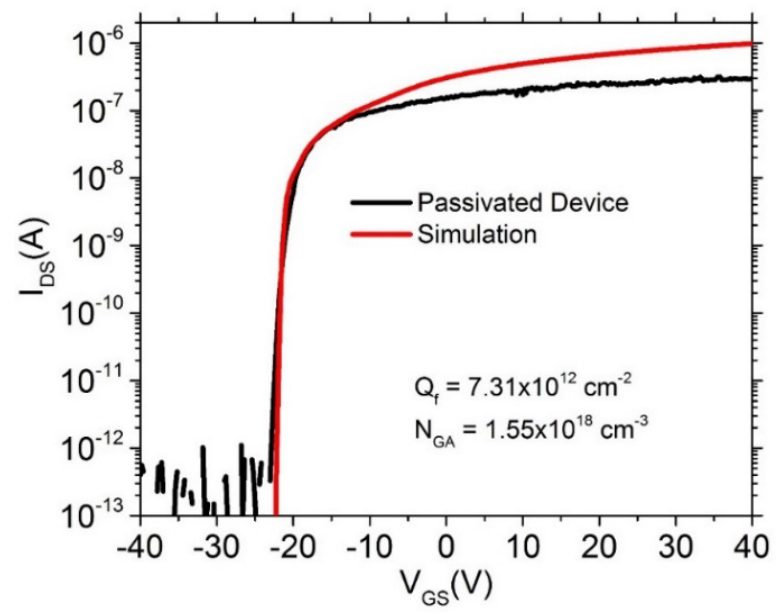

Fig.14: 3D Simulation of the passivated ZnO NWFET after increasing the density of states (DoS) parameter $\mathrm{N}_{\mathrm{GA}}$. $\mathrm{V}_{\mathrm{DS}}$ is fixed at $1.0 \mathrm{~V}$.

Fig. 15 shows 3D simulations of the passivated and unpassivated ZnO NWFETs after introducing contact resistance. To fit the experimental curves, values of $3.0 \times 10^{5} \Omega$ and $3.0 \times 10^{6} \Omega$ were needed for the unpassivated and passivated devices respectively. The simulated value for the unpassivated device is in good agreement with the measured value $\left(\mathrm{R}_{\mathrm{con}}=3.0 \times 10^{5} \Omega\right)$. However, the simulated 
value for the passivated device has higher contact resistance than experiment $\left(\mathrm{R}_{\mathrm{con}}=2.5 \times 10^{4} \Omega\right)$. The passivated device had a less steep slope than the un-passivated device which means that it suffered from higher interface state trapped charge. This must have caused the inaccuracy of the simulated contact resistance.

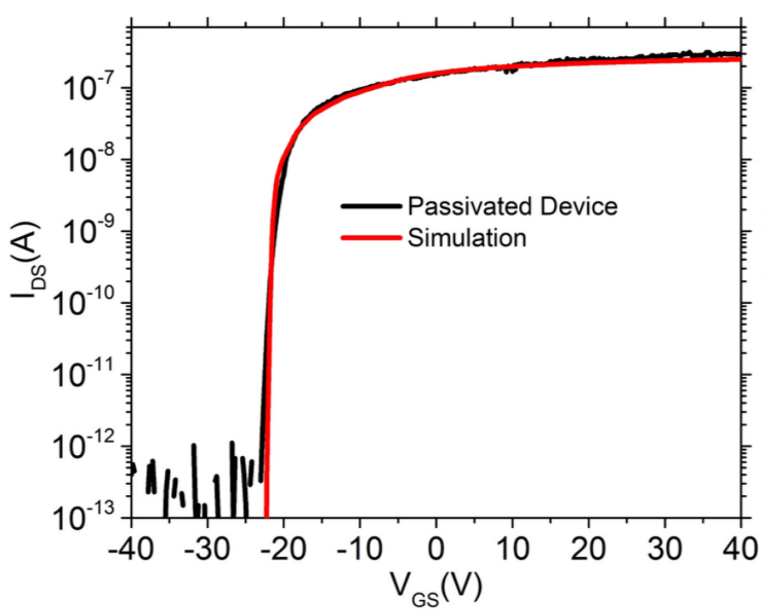

(a)

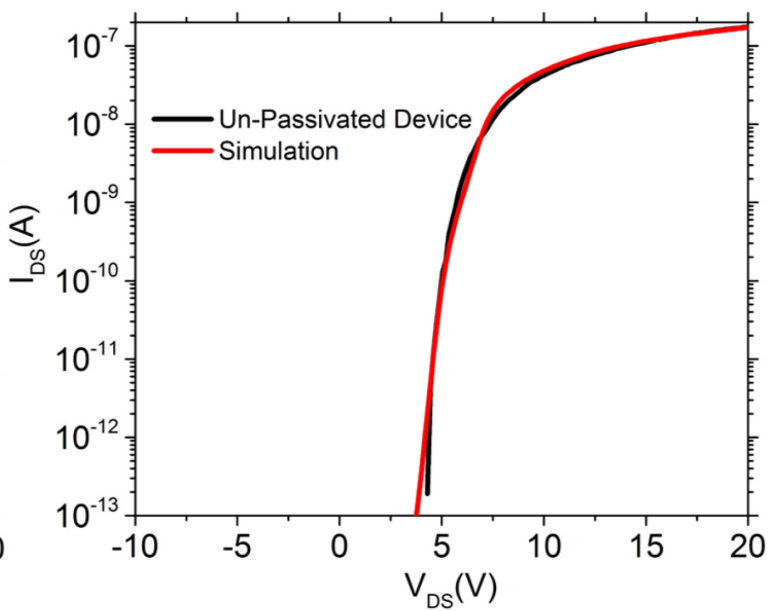

(b)

Fig.15: 3D Simulation of the $\mathrm{ZnO}$ NWFET after including contact resistance. (a) passivated $\mathrm{ZnO}$ NWFET device (b) unpassivated ZnO NWFET device. $\mathrm{V}_{\mathrm{DS}}$ is fixed at $1.0 \mathrm{~V}$.

\section{Conclusion}

Top-down $\mathrm{ZnO}$ NWFETs were successfully fabricated with and without $\mathrm{Al}_{2} \mathrm{O}_{3}$ passivation. This was done by developing a new recipe for depositing a thin film of $\mathrm{ZnO}$. By using a high donor concentration of $1.7 \times 10^{18} \mathrm{~cm}^{-3}$ for the thin film, contact resistance values were lowered (passivated has $\mathrm{R}_{\text {con }}=2.5 \times 10^{4} \Omega$; unpassivated has $\mathrm{R}_{\text {con }}=3.0 \times 10^{5} \Omega$ ). By depositing $\mathrm{Zn}$ first instead of $\mathrm{O}_{2}$, steep subthreshold slopes were obtained. The passivated device has a subthreshold slope of 225 $\mathrm{mV} /$ decade and the unpassivated device a slope of $125 \mathrm{mV} /$ decade. Well-behaved electrical characteristics have been obtained and the passivated device shows a field effect mobility of 10.9 $\mathrm{cm}^{2} / \mathrm{Vs}$ and the un-passivated device a value of $31.4 \mathrm{~cm}^{2} / \mathrm{Vs}$. Simulations have shown that these values of sub-threshold slope translate into interface state densities of $9.1 \times 10^{17} \mathrm{~cm}^{-3}$ for the unpassivated device and $1.5 \times 10^{18} \mathrm{~cm}^{-3}$ for the passivated device. The passivated device is suitable for biosensing applications.

\section{Acknowledgment}

N.M.J. Ditshego would like to acknowledge the Botswana International University of Science and Technology (BIUST) for supporting his doctoral studies and the Southampton Nanofabrication Centre for the experimental work. The authors would like to acknowledge EPSRC EP/K502327/1 grant support.

\section{Reference}

[1] C. Klingshirn, J. Fallert, H. Zhou, J. Sartor, C. Thiele, F. Maier-Flaig, D. Schneider, and H. Kalt, "65 years of $\mathrm{ZnO}$ research - old and very recent results," Phys. Status Solidi, vol. 247, no. 6, pp. 1424-1447, Apr. 2010.

[2] M. Curreli, R. Zhang, F. N. Ishikawa, H. K. Chang, R. J. Cote, C. Zhou, and M. E. Thompson, "Real-time, label-free detection of biological entities using nanowire-based FETs," IEEE Trans. Nanotechnol., vol. 7, no. 6, pp. 651-667, Nov. 2008.

[3] H. Ng, J. Han, T. Yamada, and P. Nguyen, "Single crystal nanowire vertical surround-gate field-effect transistor,” Nano Lett., vol. 4, no. 7, pp. 1247-1252, Jul. 2004. 
[4] J. Kang, K. Keem, D. Y. Jeong, and S. Kim, "Electrical characteristics of ZnO nanowirebased field-effect transistors on flexible plastic substrates," Japanese J. Appl. Physics, Part 1 Regul. Pap. Short Notes Rev. Pap., vol. 46, no. 9 B, pp. 6227-6229, Sep. 2007.

[5] S.-M. Peng, Y.-K. Su, L.-W. Ji, S.-J. Young, C.-Z. Wu, W.-B. Cheng, W.-C. Chao, and C.-N. Tsai, "Photosensitivity of Field-Effect Transistors Based on ZnO Nanowire Networks," IEEE Electron Device Lett., vol. 32, no. 3, pp. 339-341, Mar. 2011.

[6] S. M. Sultan, N. J. Ditshego, R. Gunn, P. Ashburn, and H. M. Chong, "Effect of atomic layer deposition temperature on the performance of top-down $\mathrm{ZnO}$ nanowire transistors.," Nanoscale Res. Lett., vol. 9, no. 1, p. 517, Jan. 2014.

[7] S. M. Sultan, "Top-Down Fabrication and Characterization of Zinc Oxide Nanowire Field Effect Transistors", PhD thesis, University of Southampton, April 2013.

[8] S. Kwon, S. Bang, S. Lee, and S. Jeon, "Characteristics of the $\mathrm{ZnO}$ thin film transistor by atomic layer deposition at various temperatures," Semicond., vol. 24, no. 3, p. 035015 (6 pp.), Mar. 2009.

[9] Y. Moon, S. Lee, and D. Kim, "Characteristics of ZnO based TFT using La2O3 high-k dielectrics,” J. Korean, vol. 55, no. 5, pp. 1906-1909, Nov. 2009.

[10] C. H. Ahn, D. K. Seo, C. H. Woo, and H. K. Cho, "Influence of the thermal annealing temperature of the channel layers grown at room temperature on the device performance in the ZnO thin-film-transistors,” Phys. B Condens. Matter, vol. 404, no. 23-24, pp. 4835-4838, Dec. 2009.

[11] N.M.J. Ditshego, K. Sun, I. Zeimpekis, P. Ashburn, M.R.R. de Planque, H.M.H. Chong, "Effects of surface passivation on top-down $\mathrm{ZnO}$ nanowire transistors," Microelectronic Engineering, vol. 145, pp. 91-95, Sept-2015.

[12] Zhang Hao, Zhang Liang, Li Jun, Jiang Xue-Yin, Zhang Zhi-Lin, And Zhang Jian-hua, "Improvment of ZnO-TFT Performance by Annealing ZnO Film," Chinese Journal of Luminescence, vol. 32, no. 12. pp. 1281-1285, Dec-2011.

[13] S. Park, S. Bang, S. Lee, J. Park, Y. Ko, and H. Jeon, "The Effect of Annealing Ambient on the Characteristics of an Indium-Gallium-Zinc Oxide Thin Film Transistor," J. Nanosci. Nanotechnol., vol. 11, no. 7, pp. 6029-6033, Jul. 2011.

[14] K. Keem, J. Kang, C. Yoon, D.-Y. Jeong, B.-M. Moon, and S. Kim, "Enhanced Performance of ZnO Nanowire Field Effect Transistors by H 2 Annealing,” Jpn. J. Appl. Phys., vol. 46, no. 9B, pp. 6230-6232, Sep. 2007.

[15] B. Reddy, B. R. Dorvel, J. Go, P. R. Nair, O. H. Elibol, G. M. Credo, J. S. Daniels, E. K. C. Chow, X. Su, M. Varma, M. a. Alam, and R. Bashir, "High-k dielectric A12O3 nanowire and nanoplate field effect sensors for improved $\mathrm{pH}$ sensing," Biomed. Microdevices, vol. 13, no. 2, pp. 335-344, Apr. 2011.

[16] T. E. Bae, H. J. Jang, J. H. Yang, and W. J. Cho, "High performance of silicon nanowirebased biosensors using a high- K stacked sensing thin film," ACS Appl. Mater. Interfaces, vol. 5, no. 11, pp. 5214-5218, 2013.

[17] K. Keem, D. Y. Jeong, S. Kim, M. S. Lee, I. S. Yeo, U. I. Chung, and J. T. Moon, "Fabrication and device characterization of omega-shaped-gate $\mathrm{ZnO}$ nanowire field-effect transistors," Nano Lett., vol. 6, no. 7, pp. 1454-1458, May 2006.

[18] J. Zhou, N. S. Xu, and Z. L. Wang, "Dissolving Behavior and Stability of ZnO Wires in Biofluids: A Study on Biodegradability and Biocompatibility of ZnO Nanostructures," Adv. Mater., vol. 18, no. 18, pp. 2432-2435, Sep. 2006. 
[19] K. K. N. Simon M. Sze, Semiconductor Devices: Physics and Technology, 3rd Edition [Print Replica]. Wiley; 3 edition, 2012.

[20] J. Maeng, G. Jo, S. S. Kwon, S. Song, J. Seo, S. J. Kang, D. Y. Kim, and T. Lee, "Effect of gate bias sweep rate on the electronic properties of $\mathrm{ZnO}$ nanowire field-effect transistors under different environments," Appl. Phys. Lett., vol. 92, no. 23, p. 233120, Jun. 2008.

[21] C. Hsu and T. Tsai, "Fabrication of fully transparent indium-doped $\mathrm{ZnO}$ nanowire field-effect transistors on ITO/glass substrates," J. Electrochem. Soc., vol. 158, no. 2, pp. K20-K23, Feb. 2011.

[22] S. Peng, Y. Su, and L. Ji, "Semitransparent field-effect transistors based on ZnO nanowire networks," Device Lett. IEEE, vol. 32, no. 4, pp. 533-535, Apr. 2011.

[23] C. G. Kang, J. W. Kang, S. K. Lee, S. Y. Lee, C. H. Cho, H. J. Hwang, Y. G. Lee, J. Heo, H.J. Chung, H. Yang, S. Seo, S.-J. Park, K. Y. Ko, J. Ahn, and B. H. Lee, "Characteristics of CVD graphene nanoribbon formed by a $\mathrm{ZnO}$ nanowire hardmask.," Nanotechnology, vol. 22, no. 29, p. 295201, Jul. 2011.

[24] Y. Wang, X. W. Sun, J. Zhao, G. K. L. Goh, L. Chen, L.-L. Liew, J. Qiu, And Y.-H. Hwang, "Comparison of the hydrothermal and VPT grown zno nanowire field effect transistors," International Journal of Nanoscience, vol. 09, no. 4. pp. 317-320, Aug-2010.

[25] W. I. Park, J. S. Kim, G. C. Yi, and H. J. Lee, “ZnO nanorod logic circuits,” Adv. Mater., vol. 17, no. 11, p. 1393, Jun. 2005.

[26] S. Ju, K. Lee, D. B. Janes, R. C. Dwivedi, H. Baffour-Awuah, R. Wilkins, M.-H. Yoon, A. Facchetti, and T. J. Marks, "Proton radiation hardness of single-nanowire transistors using robust organic gate nanodielectrics," Appl. Phys. Lett., vol. 89, no. 13, pg 073510, Sep. 2006.

[27] Y. Heo, L. Tien, and Y. Kwon, "Depletion-mode ZnO nanowire field-effect transistor," Appl. Phys, vol. 85, no. 12, pp. 2274-22762276, Sep. 2004.

[28] H. T. Ng, J. Han, T. Yamada, P. Nguyen, Y. P. Chen, and M. Meyyappan, "Single Crystal Nanowire Vertical Surround-Gate Field-Effect Transistor," Nano Lett., vol. 4, no. 7, pp. 1247-1252, Jul. 2004.

[29] J. Y. Park, Y. S. Yun, Y. S. Hong, H. Oh, J. J. Kim, and S. S. Kim, "Synthesis, electrical and photoresponse properties of vertically well-aligned and epitaxial $\mathrm{ZnO}$ nanorods on $\mathrm{GaN}$ buffered sapphire substrates,” Appl. Phys. Lett., vol. 87, no. 12, pp. 1-3, Sep. 2005.

[30] W. Wang, H. D. Xiong, M. D. Edelstein, D. Gundlach, J. S. Suehle, C. A. Richter, W.-K. Hong, and T. Lee, "Low frequency noise characterizations of $\mathrm{ZnO}$ nanowire field effect transistors," J. Appl. Phys., vol. 101, no. 4, Feb. 2007.

[31] H. Kim, J.-H. Park, M. Suh, J. Real Ahn, and S. Ju, "Horizontally aligned ZnO nanowire transistors using patterned graphene thin films," Appl. Phys. Lett., vol. 100, no. 6, p. 063112, 2012.

[32] S. Das, J. H. Kim, H. S. Choi, Y. K. Park, and Y. B. Hahn, "Interfacial and electrical properties of solution processed p-TiO 2 in heterojunction devices," Electrochem. commun., vol. 13, no. 4, pp. 350-354, Apr. 2011.

[33] R. Noriega, J. Rivnay, L. Goris, D. Kälblein, H. Klauk, K. Kern, L. M. Thompson, A. C. Palke, J. F. Stebbins, J. R. Jokisaari, G. Kusinski, and A. Salleo, "Probing the electrical properties of highly-doped Al:ZnO nanowire ensembles," J. Appl. Phys., vol. 107, no. 7, p. 074312 (7 pp.), Apr. 2010. 